\title{
Experimental Study on Leaching Experiment of Coal Gangue and the Pollution Analysis of Heavy Metal Concentrations Around the Coal Gangue in Lu'an Mining Area
}

\author{
Yang Wang ${ }^{1, a}$ \\ ${ }^{1}$ College of Geoscience and Surveying Engineering, China University of Mining and Technology \\ (Beijing), Beijing 100083, China \\ a18911912453@163.com
}

\begin{abstract}
Keywords: heavy metal element pollution; coal gangue; soil; leaching experiment; pollution assessment

Abstract. In order to investigate the effect of heavy metals of the gangue on the surrounding soil, fresh gangue and soil samples along from certain gangue mountain were collected. Nine heavy metals of $\mathrm{Cu}, \mathrm{Pb}, \mathrm{Zn}, \mathrm{Cd}, \mathrm{Ni}, \mathrm{Cr}, \mathrm{As}, \mathrm{Hg}$ and $\mathrm{Ba}$ were detected and the relevance of gangue and soils was analyzed. Several pollution indexes were also used to evaluate the influences of heavy metal pollutants on environmental quality. From the result, $\mathrm{Pb}, \mathrm{Cd}$ and $\mathrm{Cu}$ elements of leaching immersion in Qiyi, Xiadian and Huipo coal mines exceeded the third kind standard of surface water. The soil surrounding the gangue piling site was relatively safe.
\end{abstract}

\section{Introduction}

The coal gangue is one of the solid wastes in the coal mining process, and is also a concomitant low heat, high-ash carbonaceous rocks ${ }^{[1]}$. The coal gangue contains a variety of trace metals, sulfides and a lot of organic pollutants ${ }^{[2]}$. The coal gangue in leaching solution is bound to affect the surrounding soil environment ${ }^{[3]}$. The Lu'an mining area is located in the southeast of Shanxi Province, with more than 50 years of development history. The 22 large coal gangue piles were invested in Lu'an Mining Area ${ }^{[4]}$. Although Lu'an mine strongly supported the national economy of Shanxi Province, a large number of coal gangues have become one of the main sources of mine. To this end, for the rational development of coal mining resources and protecting the ecological environment, we need to analyze the types of trace heavy metal elements of coal gangues and soil samples, and the effect of heavy metals of the gangue on the surrounding soil.

\section{Methods}

The collection of coal gangue and soil samples used the principle of combined regional surveillance and encryption key sections. The 32 samples were collected in different locations of large gangues of mining area. According to the different location of the gangue, we collected soil samples near the gangue piles or along the valley downstream of the gangue piles. Following a waste dump horizontal distance interval 5m, 15m, 50m, 3 group 9 samples were collected. The depth of each sample was $0.6 \mathrm{~m}$ and the weight of each sample was no more than $2 \mathrm{~kg}$. We have studied the leaching experiment of the 32 gangue samples and 9 soil samples, analyzed the types of trace heavy metal elements of coal gangues and soil samples, and evaluated the effect of heavy metals of the gangue on the surrounding soil ${ }^{[5]}$.

According to the method of identification standards for hazardous wastes-identification for extraction toxicity(GB5085.3-2007) ${ }^{[6]}$, we mainly used the method of inductively coupled plasma atomic emission spectrometry (ICP-AES) to determine the contents of heavy metal elements in each sample at environmental temperature of $20^{\circ} \mathrm{C}^{[7]}$, humidity of $10 \mathrm{RH} \%$, used the method of glass electrode (GB6920-86*) to determine the $\mathrm{pH}$ value of samples, and used the method of atomic fluorescence spectrometry (GB5085.3-2007) to determine contents of arsenic and its compounds ${ }^{[8]}$. 


\section{Results and Discussion}

According to the amount of leaching immersion of heavy metals element of the gangue for Lu'an mining area, nine elements have been divided into two groups: one group of $\mathrm{Pb}, \mathrm{Cu}, \mathrm{Ba}$ and $\mathrm{Ni}$ elements with larger overall content, another group of five other elements with the smaller. The primarily reason for a larger amount content of the first group elements is influenced by water environment and easily transferred to the runoff by precipitation. The amount of heavy metals element of leaching immersion in Qiyi, Xiadian and Huipo coal mines is higher than the other coal mines.

The figure 1 shows that the contents of $\mathrm{Pb}, \mathrm{Cu}, \mathrm{Ba}$ elements among the three mines have a rapid increase, only $\mathrm{Ni}$ element remained relatively stable in the first set of element. The contents of $\mathrm{Pb}$, $\mathrm{Cu}, \mathrm{Cd}, \mathrm{Zn}, \mathrm{Ni}$ and As elements of gangue samples for Qiyi coal is the largest of all the samples. $\mathrm{Pb}$ concentration is $0.82 \mathrm{mg} / \mathrm{L}$ and is17 times the third kind standard of Surface Water Quality Standards (GB3838-2002). The contents of $\mathrm{Cd}$ and $\mathrm{Cu}$ elements are more than the third kind standard of Surface Water Quality Standards. As dipping into the surrounding soil with leaching immersion, the excessive heavy metal elements can cause the pollution of the surrounding water or soil.

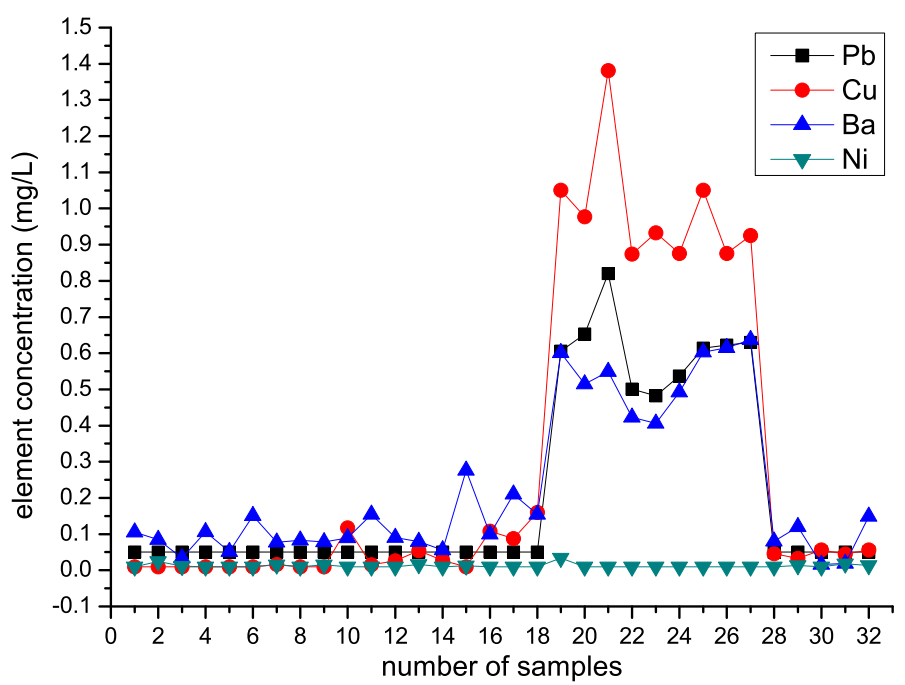

Fig. 1 Distribution of major heavy metal element concentration for coal gangue in Lu'an mining area

The contents of $\mathrm{Pb}, \mathrm{Cu}, \mathrm{Ba}$ and $\mathrm{Ni}$ elements of soil samples are relatively large in Qiyi, Xiadian and Huipo coal mines, which is consistent with the characteristic of gangue leaching, indicating that these four elements may be adsorbed by the soil infiltration in soil. The contents of $\mathrm{Zn}$ and As in soil samples are larger than coal gangue samples, which may be due to some heavy metal elements of coal gangue in the long-term effect of rainfall runoff formed gradually have enriched in some downstream low-lying valley. According to figure 2 and figure 3 show that the contents of heavy metal elements in Lu'an mining area have a steady decline trend with the increase of distance from coal gangue and smaller content of heavy metal elements have little change. These indicate that the coal gangue for the heavy metals content in the soil has a considerable impact. Comprehensive the above conclusions, the heavy metal elements in coal gangue leaching solution are absorbed into the soil by osmosis adsorption of the soil, increase the surrounding soil heavy metal content, but not yet to cause soil environmental pollution. 

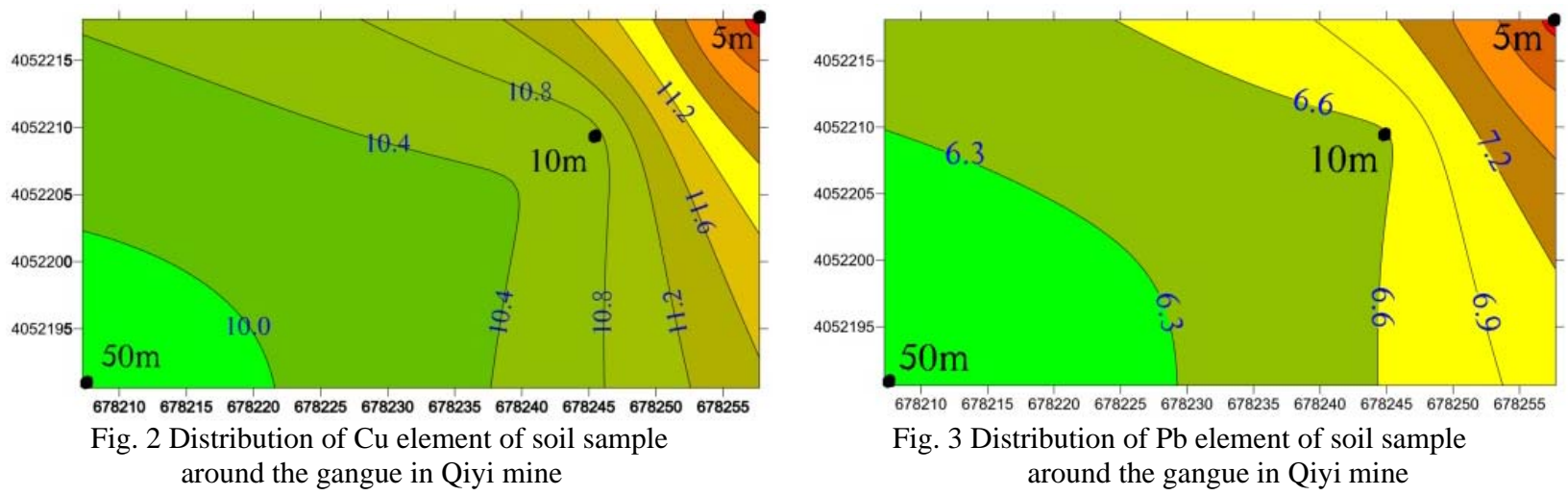

\section{Conclusions}

Through the analysis of leaching experiment of coal gangue and soil samples, the content of trace heavy metals in Lu'an coal mine is relatively low except that $\mathrm{Pb}, \mathrm{Cd}$ and $\mathrm{Cu}$ elements of leaching immersion in Qiyi, Xiadian and Huipo coal mines exceeded the third kind standard of surface water. The coal gangue leaching solution is neutral or alkaline, mainly because of the more waste alkali and alkaline earth metal compounds neutralize the acid such as $\mathrm{FeS}_{2}$.

The contents of $\mathrm{Pb}, \mathrm{Cu}, \mathrm{Ba}$ and $\mathrm{Ni}$ elements of soil samples are relatively large in Qiyi, Xiadian and Huipo coal mines, which is consistent with the characteristics of gangue leaching, indicating that these four elements may be adsorbed by the soil infiltration in soil. The contents of heavy metal elements in Lu'an mining area have a steady decline trend with the increase of distance from coal gangue and smaller content of heavy metal elements have little change. These indicate that the coal gangue for the heavy metals content in the soil has a considerable impact.

Through the pollution evaluation of soil heavy metals, soil pollution level is in the safe range. But due to long-term pile of the gangue, the enrichment of heavy metal elements of leaching solution may bring harm to the surrounding environment. Therefore, it is suggested that the content of heavy metals for waters and plants around the gangue should be detected and develop a scientific and reasonable management measures to prevent harm to human health and ecological environment.

\section{References}

[1] Brake S S, Connors K A. A river runs through it: impact of acid mine drainage on the geochemistry of west little Sugar Creek pre-and postrecl-amation at the Green Valley coal mine, Indiana, USA [J]. Environmental Geology, 2001, 40: 1471-1481.

[2] Ghosh R S, Saigal S, Dzombak D. Assessment of in Situ Solvent Extraction with Interrupted Pumping for Remediation of Subsurface Coal Tar Contamination [J].Water Environment Research, 1997, 69(3): 295 304.

[3] Fanfanl L, Zuddas P, Chessa A. Heavy metals speciation analysis as a tool for studying mine tailing weathering [J]. Journal of Geochemical Exploration, 2004, 58(2/3): 241-248.

[4] Maria I, Xavier Q. Leaching behavior of elements from coal combustion fly ash: An overview [J].International Journal of Coal Geology, 2012, (94): 54 66.

[5] Browning L, Murphy W M, Manepally C. Reactive transport model for the ambient unsaturated hydro-system at Yucca Mountain in Nevada [J]. Computers and Geosciences, 2003, 29(3):247 263.

[6] Kalbitz K, Bad L, Wennrich R. Mobilization of heavy metals and arsenic in polluted wetland soils and its dependence on dissolved organic matter [J]. Sci Tot al Environ, 1998, 209(1): 27-39. 
[7] ROMERO-PUERTAS M C, CORPAS F J, RODR GUEZ-SERRANO M, et al. Differential expression and regulation of antioxidative enzymes by cadmium in pea plants [J]. Journal of Plant Physiology, 2007, 164(10): 1346-1357.

[8] EKMEKCI Y, TANYOLAC D, AYHAN B. Effects of cadmium on antioxidant enzymeand photosynthetic activities in leaves of two maize cultivars [J]. Journal of Plant Physiology, 2008, 165(6): 600-611. 